10) Verniory, A., R. Du Bois, P. Decoodt, J. P. Gassee and P. P. Lambert: J. Gen. Physiol., 62, 489 (1973).

11) Wang, N. H. L. and K. H. Keller: Trans. Am. Soc. Artif. Intern. Organs, 25, 14 (1979).

12) Zydney, A. L. and C. K. Colton: Trans. Am. Soc. Artif. Intern.
Organs, 28, $408(1982)$

(Presented in part at the 51st Annual Meeting of The Society of Chemical Engineering, Japan, at Osaka, March 1986.)

\title{
STRUCTURAL ANALYSIS OF HOLLOW FIBER DIALYSIS MEMBRANES FOR CLINICAL USE
}

\author{
KIYOTAKA SAKAI, SHINGO TAKESAWA, RISHICHI MIMURA \\ AND HIDEHIKO OHASHI \\ Department of Chemical Engineering, Waseda University, Tokyo 160
}

Key Words: Dialysis Membrane, Pore Radius, Solute Permeability, Pure Water Permeability, Surface

Porosity, Tortuosity, Water Content

\begin{abstract}
Little is known of the structure of hollow-fiber dialysis membranes for clinical use or of the effects of structure on solute and pure water permeability. Knowledge of such aspects of membrane structure as pore radius, surface porosity, tortuosity and water content is required if the desired membranes are to be designed.

The objective of the present study, therefore, is to obtain data on the pore radius, surface porosity and tortuosity of hollow-fiber dialysis membranes through an analysis of measured water content, and of solute and pure water permeability on the basis of a newly introduced tortuous pore model. In regenerated cellulose membranes, pore radius ranges from 21 to $34 \times 10^{-10} \mathrm{~m}$, and huge pores ranging in radius from 47 to $64 \times 10^{-10} \mathrm{~m}$ are identified for EVA membranes which are permeable to small amounts of serum protein. Values for surface porosity of the regenerated cellulose and EVA membranes are approximately 33 and $22 \%$, and tortuosity is approximately 1.9 and 2.2, respectively. The tortuous pore model combined with the $L_{p}$ and $P_{m}$ method is well suited for elucidating the relationship between membrane structure and solute and pure water permeability.
\end{abstract}

\section{Introduction}

The performance of currently utilized hemodialyzers is absolutely dependent on the permeability of their membranes. Appropriate design of dialysis membranes requires correct values for pore radius, surface porosity, water content and tortuosity. It has proved impossible to find the pore radius of dialysis membranes using the mercury porosimeter or electron microscope because the pores are only several tens of angstroms in radius. Consequently, indirect procedures such as the $L_{p}$ method that uses both pure water permeability and water content, ${ }^{1}$ the $L_{p}$ and $P_{m}$ method, which uses both pure water and solute permeability ${ }^{4,5,7,8)}$ and the $\sigma$ method that uses the reflection coefficient ${ }^{3,8,14)}$ have been employed extensively. Structural data obtained from the procedures referred to above may lack reliability, however, because those procedures depend on a simplified pore model that assumes that membrane pores are formed

Received October 1, 1986. Correspondence concerning this article should be addressed to K. Sakai. perpendicular to the membrane surface.

The objective of the present study is to obtain data on the pore radius, surface porosity and tortuosity of hollow-fiber dialysis membranes through an analysis of measured water content, and of solute and pure water permeability on the basis of a newly introduced tortuous pore model.

\section{Theoretical}

Kedem and Katchalsky ${ }^{2)}$ derived phenomenological transport equations based on nonequilibrium thermodynamics. In this analysis, membrane characteristics are expressed as three transport parametersreflection coefficient, and solute and pure water permeability. The membrane is considered to be a black box.

The simplified pore model ${ }^{7)}$ directly relating membrane structure to these transport parameters was improved by Verniory ${ }^{13)}$ and Kimura ${ }^{6)}$ with tortuosity omitted in any pore model. Qualitative attempts to account for tortuosity in the pore model have been successful. ${ }^{9)}$ 
Tortuosity $\tau$ may be defined as the ratio of pore length to wall thickness:

$$
\tau=L / \Delta x
$$

The pore model was further improved to produce the following equations:

$$
\begin{aligned}
& L_{p}=\left(r_{p}^{2} / 8 \mu\right)\left(A_{k} / \tau / \Delta x\right) \\
& P_{m}=D_{W} f(q) S_{D}\left(A_{k} / \tau / \Delta x\right)
\end{aligned}
$$

where

$$
\begin{aligned}
f(q)= & \left(1-2.105 q+2.0865 q^{3}-1.7068 q^{5}\right. \\
& \left.+0.72603 q^{6}\right) /\left(1-0.75857 q^{5}\right) \\
S_{D}= & (1-q)^{2} \\
q= & r_{s} / r_{p}
\end{aligned}
$$

From Eqs. (2) and (3),

$$
P_{m} / L_{p}=f(q) S_{D}\left(8 \mu D_{W} / r_{p}^{2}\right)
$$

which is identical with the equation obtained by Klein. ${ }^{4)}$

Structural parameters such as surface porosity, tortuosity and wall thickness involved in the pore model disappear in Eq. (7). Measurements of solute and pure water permeability provide pore radius by iteration without using surface porosity, water content, tortuosity or wall thickness. Values for $A_{k} /(\tau \cdot \Delta x)$ can be obtained by substituting pore radius and pure water permeability data in Eq. (2).

The pore length in Eq. (1) cannot be measured in a straightforward way. Water is capable of permeating the amorphous region of the crystalline polymer that forms the pores in dialysis membranes. The water content approximates pore volume ratio under wet conditions. The tortuosity defined in Eq. (1) can be alternatively expressed as

$$
\begin{aligned}
\tau & =\frac{\left(n A_{p} L\right) / V_{m}}{\left(n A_{p} \Delta x\right) / V_{m}} \\
& =\frac{\left(n A_{p} L\right) / V_{m}}{\left(n A_{p}\right) / A_{m}} \\
& =\frac{H}{A_{k}}
\end{aligned}
$$

Here $\tau$ and $A_{k}$ can be calculated from Eqs. (9) and (10).

$$
\begin{aligned}
\tau & =\sqrt{H / \Delta x /\left(A_{k} / \tau / \Delta x\right)} \\
A_{k} & =\sqrt{H \Delta x\left(A_{k} / \tau / \Delta x\right)}
\end{aligned}
$$

In the tortuous pore model presented here, dialysis membranes are assumed to be of symmetrical structure. With imperfectly symmetrical dialysis membranes, structural parameters obtained by the tor- tuous pore model are averaged over pore length.

\section{Experimental}

\subsection{Materials}

Table 1 summarizes technical data on the capillary dialyzers tested. Hollow-fiber dialysis membranes prepared from polymers such as regenerated cellulose (RC), ethylenevinyl alcohol (EVA) and polymethyl methacrylate (PMMA) are skinfree and of imperfectly symmetrical structure.

Stokes radius and diffusivity at $310 \mathrm{~K}$ are as follows: ${ }^{12}$

$$
\begin{aligned}
& \text { Urea } \quad r_{s}=1.82 \times 10^{-10} \mathrm{~m} \\
& D_{W}=1.81 \times 10^{-9} \mathrm{~m}^{2} \cdot \mathrm{s}^{-1} \\
& \text { Glucose } \quad r_{s}=3.61 \times 10^{-10} \mathrm{~m} \\
& D_{W}=9.09 \times 10^{-10} \mathrm{~m}^{2} \cdot \mathrm{s}^{-1} \\
& \text { Sucrose } \quad r_{s}=4.71 \times 10^{-10} \mathrm{~m} \\
& D_{W}=6.97 \times 10^{-10} \mathrm{~m}^{2} \cdot \mathrm{s}^{-1}
\end{aligned}
$$

Water viscosity at $310 \mathrm{~K}$ is $6.947 \times 10^{-4} \mathrm{~Pa} \cdot \mathrm{s}$.

\subsection{Apparatus}

The experimental apparatus shown in Fig. 1 was utilized to measure solute permeability at a dialysate flow rate (Fig. 2) sufficient to eliminate the boundary layer formed outside the membrane tube.

\subsection{Procedures}

The slope of the plot of TMP (transmembrane pressure) vs. ultrafiltration rate provides pure water permeability. Solute permeability was determined by a newly improved method using ${ }^{14} \mathrm{C}$-labeled urea, glucose and sucrose.

The following procedure was used:

1. The hollow-fiber membranes available from the dialyzers tested were cut into shorter lengths, and the effective length was kept to $0.1 \mathrm{~m}$ by equipping each membrane with polyethylene tubes (ID $1 \mathrm{~mm}$; OD $2 \mathrm{~mm}$ ) at either end.

2. The membranes were placed in pure water at $310 \mathrm{~K}$ for $12 \mathrm{~h}$ to completely wet them.

3. The hollow was filled with the desired radioactive solute in pure water containing $5 \mathrm{Cim}^{-3}$ after water removal and the membrane was sealed with clay. Dialysis experiments were then conducted for a predetermined time.

4. The amount of radioactive solute remaining in the sealed membrane tube was determined, using an Aloka-900LSC liquid scintillation counter.

Five or more measurements were made for various dialysis times to obtain exact values for solute permeability, and data were analyzed by the method of Stevenson. ${ }^{10,11)}$ One hundred wet membrane tube sections were observed under a microscope to determine both inner diameter and wall thickness when 
Table 1. Technical data on capillary dialyzer

\begin{tabular}{|c|c|c|c|c|c|c|}
\hline \multirow[b]{2}{*}{$\begin{array}{l}\text { Dialyzer } \\
\text { (Manufacturer) }\end{array}$} & \multirow{2}{*}{$\begin{array}{c}\text { Number } \\
\text { of } \\
\text { fibers }\end{array}$} & \multirow[b]{2}{*}{ Material } & \multirow[b]{2}{*}{$\begin{array}{c}\begin{array}{c}\text { Surface } \\
\text { area }\end{array} \\
{\left[\mathrm{m}^{2}\right]}\end{array}$} & \multicolumn{3}{|c|}{ Membrane } \\
\hline & & & & $\begin{array}{c}\text { Inner } \\
\text { diameter } \\
\times 10^{6}[\mathrm{~m}]\end{array}$ & $\begin{array}{l}\text { Wall thickness } \\
\quad \times 10^{6}[\mathrm{~m}]\end{array}$ & $\begin{array}{l}\text { Fiber length } \\
\quad \times 10^{3}[\mathrm{~m}]\end{array}$ \\
\hline $\begin{array}{l}\text { MC } 0.8 \mathrm{H} \\
\quad \text { (Senko Med. Co., Ltd.) }\end{array}$ & 6,600 & Cuprophan ${ }^{(i)}$ & 0.72 & 200 & 8 & 172 \\
\hline $\begin{array}{l}\text { TAF } 10 \\
\quad \text { (Terumo Co., Ltd.) }\end{array}$ & 6,850 & $\begin{array}{l}\text { Regenerated } \\
\text { cellulose }\end{array}$ & 1.02 & 200 & 12 & 237 \\
\hline $\begin{array}{l}\text { AM-10 } \\
\quad \text { (Asahi Med. Co., Ltd.) }\end{array}$ & 10,700 & $\begin{array}{l}\text { Regenerated } \\
\text { cellulose }\end{array}$ & 1.18 & 200 & 15 & 176 \\
\hline $\begin{array}{l}\text { AM-2000U } \\
\text { (Asahi Med. Co., Ltd.) }\end{array}$ & 10,900 & $\begin{array}{l}\text { Regenerated } \\
\text { cellulose }\end{array}$ & 1.49 & 200 & 8 & 218 \\
\hline $\begin{array}{l}\text { KF-101 } \\
\quad \text { (Kuraray Co., Ltd.) }\end{array}$ & 7,800 & $\begin{array}{l}\text { Ethylenevinyl } \\
\text { alcohol }\end{array}$ & 1.21 & 200 & 32 & 246 \\
\hline $\begin{array}{l}\text { KF-101C } \\
\quad \text { (Kuraray Co., Ltd.) }\end{array}$ & 7,800 & $\begin{array}{l}\text { Ethylenevinyl } \\
\text { alcohol }\end{array}$ & 1.23 & 200 & 32 & 250 \\
\hline $\begin{array}{l}\text { KPK-101 } \\
\quad \text { (Kuraray Co., Ltd.) }\end{array}$ & 6,528 & $\begin{array}{l}\text { Ethylenevinyl } \\
\text { alcohol }\end{array}$ & 1.26 & 250 & 33 & 245 \\
\hline $\begin{array}{l}\text { B2-100 } \\
\quad \text { (Toray Med. Co., Ltd.) }\end{array}$ & 11,000 & $\begin{array}{l}\text { Polymethyl } \\
\text { methacrylate }\end{array}$ & 1.21 & 200 & 25 & 175 \\
\hline
\end{tabular}

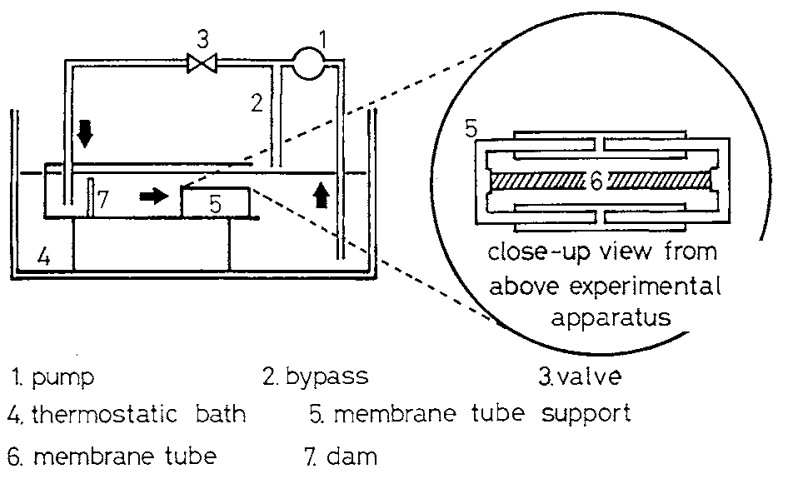

Fig. 1. Experimental apparatus for measuring solute permeability.

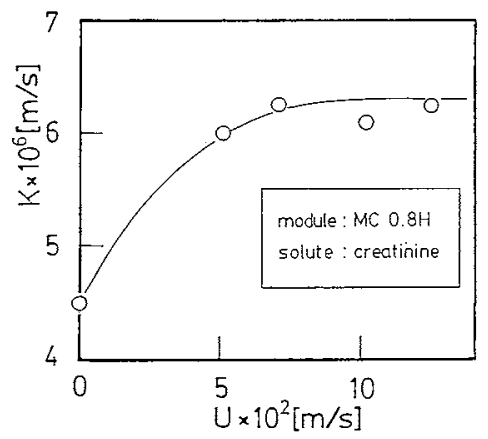

Fig. 2. Effects of dialysate flow rate on overall mass transfer coefficient for creatinine.

wet. Water content was measured by the standard method using 120 membrane tubes $5 \times 10^{-2} \mathrm{~m}$ in length.

\section{Results}

\subsection{Inner diameter and wall thickness of wet hollow- fiber dialysis membranes}

Table 2 summarizes both the inner diameter and
Table 2. Inner diameter and wall thickness of hollowfiber dialysis membranes

\begin{tabular}{lcc}
\hline Dialyzer & $\begin{array}{c}\text { Inner } \\
\text { diameter* } \\
\times 10^{6}[\mathrm{~m}]\end{array}$ & $\begin{array}{c}\text { Wall thickness* } \\
\times 10^{6}[\mathrm{~m}]\end{array}$ \\
\hline & $212 \pm 13$ & $20.7 \pm 2.8$ \\
MC 0.8H & $203 \pm 11$ & $26.4 \pm 2.9$ \\
TAF 10 & $204 \pm 22$ & $30.7 \pm 2.4$ \\
AM-10 & $200 \pm 12$ & $19.2 \pm 2.2$ \\
AM-2000U & $228 \pm 14$ & $41.1 \pm 5.2$ \\
KF-101 & $220 \pm 10$ & $44.3 \pm 4.2$ \\
KF-101C & $251 \pm 23$ & $51.8 \pm 5.2$ \\
KPK-101 & $202 \pm 7$ & $25.3 \pm 2.4$ \\
B2-100 & \\
\hline
\end{tabular}

* Data taken under wet conditions and expressed in mean \pm S.D.; $N=100$.

wall thickness of the hollow-fiber dialysis membranes tested under wet conditions. The wet RC membranes swelled two- or threefold in wall thickness. The wet EVA membranes exhibited some increase in wall thickness but almost no alteration in inner diameter because of the resistance to inward expansion.

\subsection{Solute permeability}

Table 3 summarizes the measured values for solute permeability of the membranes tested. The solute permeability of the $\mathrm{RC}$ membranes was highly dependent on wall thickness. Because of their greater thickness, synthetic polymer membranes are permeated more slowly than $\mathrm{RC}$ membranes by substances of small molecular weight. The EVA membranes permeable to small amounts of serum albumin appear to have huge pores, and middle molecules (MM) may adequately permeate them. 
Table 3. Water content, solute and pure water permeability data of hollow-fiber dialysis membranes

\begin{tabular}{|c|c|c|c|c|c|}
\hline \multirow{2}{*}{ Dialyzer } & \multicolumn{3}{|c|}{ Solute permeability $\times 10^{6}\left[\mathrm{~m} \cdot \mathrm{s}^{-1}\right]^{*}$} & \multirow{2}{*}{$\begin{array}{c}\text { Pure water permeability } \\
L_{p} \times 10^{11}\left[\mathrm{~m}^{3} \cdot \mathrm{m}^{-2} \cdot \mathrm{s}^{-1} \cdot \mathrm{Pa}^{-1}\right]^{* *}\end{array}$} & \multirow{2}{*}{$\begin{array}{l}\text { Water conten } \\
H[\mathrm{v} / \mathrm{v} \%]^{* * *}\end{array}$} \\
\hline & Urea (62) & Glucose $(180)$ & Sucrose $(342)$ & & \\
\hline $\mathrm{MC} 0.8 \mathrm{H}$ & $11.6 \pm 3.7 \quad(20)$ & $4.79 \pm 0.35(12)$ & $2.66 \pm 0.19(15)$ & 1.11 & 66 \\
\hline TAF 10 & $8.42 \pm 0.23(4)$ & $2.83 \pm 0.06(4)$ & $2.16 \pm 0.05(4)$ & 1.12 & 61 \\
\hline AM-10 & $7.83 \pm 0.13(15)$ & $3.08 \pm 0.09(10)$ & $1.80 \pm 0.10(10)$ & 0.588 & 65 \\
\hline AM-2000U & $12.2 \pm 1.1(5)$ & $5.15 \pm 0.12(6)$ & $3.06 \pm 0.07(5)$ & 1.58 & 61 \\
\hline KF-101 & $3.52 \pm 0.17(11)$ & $1.83 \pm 0.08(10)$ & $0.91 \pm 0.05(10)$ & 0.936 & 46 \\
\hline $\mathrm{KF}-101 \mathrm{C}$ & $4.02 \pm 0.08(10)$ & $1.81 \pm 0.03(8)$ & $1.08 \pm 0.03(8)$ & 1.64 & 49 \\
\hline KPK-101 & $5.23 \pm 0.29(7)$ & $2.41 \pm 0.04(4)$ & $1.42 \pm 0.04(4)$ & 2.31 & nil \\
\hline$B 2-100$ & $6.51 \quad(1)$ & $2.94^{-} \quad(1)$ & $2.11 \quad(1)$ & 0.638 & 54 \\
\hline $\begin{array}{r}\text { * Data } \\
* * \text { Data } \\
\text { ** Data }\end{array}$ & $\begin{array}{l}\text { essed in mean } \pm \text { S.I } \\
\text { ured at } 310 \mathrm{~K} \text {. } \\
\text { ured at room temp }\end{array}$ & & & & \\
\hline
\end{tabular}

\subsection{Pure water permeability}

Pure water permeability increases significantly with pore radius. Measured values for pure water permeability in Table 3 indicate the presence of an appreciable number of huge pores on such EVA membranes as $\mathrm{KF}-101 \mathrm{C}$ and $\mathrm{KPK}-101$. Among the RC membranes, AM-2000U provided the highest pure water permeability. KPK-101, with greater thickness than $\mathrm{KF}-101 \mathrm{C}$, possessed higher pure water permeability.

\subsection{Water content}

Water content is easily measurable and provides a reliable parameter for controlling the permeability of dialysis membranes, and permeability is directly proportional to water content for a specified membrane. However, water content merely represents the volume fraction of pores in the membranes, and cannot be used to find the permeability of different kinds of dialysis membranes. It is thus necessary to know pore radius, surface porosity and tortuosity as well as water content to reveal the structure of a membrane and the effects of structure on solute and pure water permeability.

\section{Discussion}

\subsection{Solute permeability}

Figure 3 shows the dependence of solute permeability on the Stokes radius of the solutes tested for typical membranes of regenerated cellulose ( $\mathrm{MC} 0.8 \mathrm{H}$ and TAF10) and synthetic polymer (KF-101). All membranes showed linear relationships. The RC membranes possessed the highest permeability for substances with a molecular weight of below 500 daltons, mainly because of their lesser thickness. The difference in solute permeability between $\mathrm{MCO} .8 \mathrm{H}$ and TAF10 can be also explained in terms of wall thickness.

4.2 $P_{m} / L_{p}$ and $r_{p}\left(L_{p}\right.$ and $P_{m}$ method)

According to the tortuous pore model, $P_{m} / L_{p}$ is a

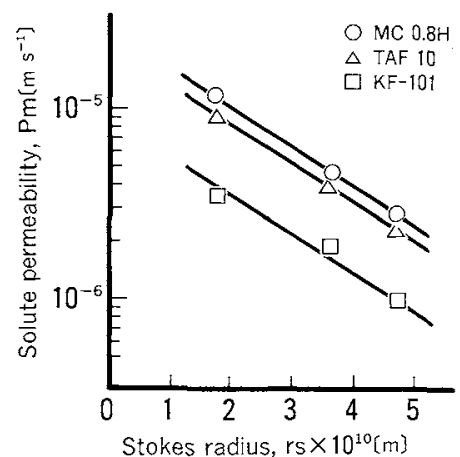

Fig. 3. Dependence of solute permeability on Stokes radius for $\mathrm{MC} 0.8 \mathrm{H}$, TAF 10 and $\mathrm{KF}-101$.

function of both Stokes radius $r_{s}$ and pore radius $r_{p}$. Since $P_{m} / L_{p}$ is expressed as a polynomial of $r_{p}$ for a specified solute, several values for pore radius can be obtained. The measured value of $P_{m} / L_{p}$ usually provides two values for pore radius. A theoretically appropriate pore radius was determined by excluding other values with an abnormally high surface porosity.

\section{$4.3 r_{p 1}, A_{k}$ and $\tau$}

Table 4 summarizes values for pore radius $r_{p 1}$ iteratively calculated using Eq. (7) for hollow-fiber dialysis membranes. Pore radius $r_{p 1}$ is a mean value because dialysis membranes usually have a pore radius distribution and are of imperfectly symmetrical structure. All membranes had practically the same pore radius for the three solutes tested.

The tortuosity of membrane pores is defined in Eq. (1) and was calculated by Eq. (9). Surface porosity was also calculated by Eq. (10). Calculated values for $\tau$ and $A_{k}$ are summarized in Table 4. A higher tortuosity implies a convoluted passage for solute transport, causing reduced solute and pure water permeability. The synthetic polymer membranes possess a higher tortuosity. Surface porosity affecting solute and pure water permeability is lowered in synthetic 
Table 4. Calculation of $r_{p 1}, A_{k} /(\tau \cdot \Delta x), A_{k}$ and $\tau$ by $L_{p}$ and $P_{m}$ method

\begin{tabular}{|c|c|c|c|c|c|c|c|c|c|c|}
\hline \multirow{2}{*}{ Dialyzer } & \multicolumn{4}{|c|}{$r_{p 1} \times 10^{10}[\mathrm{~m}]$} & \multicolumn{4}{|c|}{$A_{\mathrm{k}} /(\tau \cdot \Delta x) \times 10^{-3}\left[\mathrm{~m}^{-1}\right]$} & \multirow{2}{*}{$A_{k}[\%]$} & \multirow{2}{*}{$\tau[-]$} \\
\hline & Urea & Glucose & Sucrose & Mean & Urea & Glucose & Sucrose & Mean & & \\
\hline $\mathrm{MC} 0.8 \mathrm{H}$ & 26.6 & 24.4 & 26.0 & 25.7 & 8.62 & 10.4 & 9.02 & 9.35 & 34 & 1.9 \\
\hline TAF-10 & 32.3 & 36.0 & 32.1 & 33.5 & 5.91 & 4.85 & 6.10 & 5.62 & 31 & 2.0 \\
\hline AM-10 & 23.0 & 20.6 & 19.7 & 21.1 & 6.12 & 7.75 & 8.50 & 7.46 & 35 & 1.9 \\
\hline AM- $2000 \mathrm{U}$ & 31.8 & 30.2 & 32.0 & 31.3 & 8.59 & 9.64 & 8.33 & 8.85 & 32 & 1.9 \\
\hline KF-101 & 47.5 & 42.3 & 51.4 & 47.1 & 2.29 & 2.92 & 1.95 & 2.39 & 21 & 2.2 \\
\hline $\mathrm{KF}-101 \mathrm{C}$ & 60.3 & 60.1 & 66.5 & 62.3 & 2.53 & 2.57 & 2.10 & 2.40 & 23 & 2.1 \\
\hline KPK-101 & 62.5 & 61.6 & 68.8 & 64.3 & 3.26 & 3.42 & 2.74 & 3.14 & nil & nil \\
\hline B2-100 & 26.8 & nil & nil & 26.8 & 4.84 & nil & nil & 4.84 & 25 & 2.2 \\
\hline
\end{tabular}

polymer membranes. The surface porosity and water content of $\mathrm{AM}-10$ and $\mathrm{MC} 0.8 \mathrm{H}$ are higher than those of the other RC membranes.

\subsection{Pore radius $r_{p 2}$ based on the $L_{p}$ method}

To determine pore radius $r_{p 2}$ by the $L_{p}$ method, we need pure water permeability, water content and wall thickness but not tortuosity. Eq. (11) provides pore radius $r_{p 2}$ for the membranes tested:

$$
L_{p}=\left(r_{p 2}^{2} / 8 \mu\right)(H / \Delta x)
$$

Table 5 shows values for pore radius $r_{p 2}$, and all values are lower than those for pore radius $r_{p 1}$ obtained from Eq. (7). KF-101 membrane possesses a much smaller pore radius $r_{p 2}$ than the Stokes radius $r_{s}$ of serum albumin, and this does not accord with the fact that KF-101 membrane is permeable to serum albumin to some extent.

\subsection{Pore radius $\boldsymbol{r}_{p 3}$ based on the $\boldsymbol{P}_{m}$ method}

Using the $P_{m}$ method, pore radius $r_{p 3}$ can be calculated from solute permeability, water content and wall thickness; again tortuosity is not needed.

$$
P_{m}=D_{W} f(q) S_{D}(H / \Delta x)
$$

Table 5 summarizes values for $r_{p 3}$ calculated by Eq. (12). The values for $r_{p 3}$ are even lower than those for $r_{p 2}$. With Nuclepore membranes, pore radius $r_{p 2}$ and $r_{p 3}$ appear to be almost the same as $r_{p 1}$ because the tortuosity is close to unity.

\section{Conclusions}

1. It was found that $\mathrm{RC}$ membranes had a mean pore radius from 21 to $34 \times 10^{-10} \mathrm{~m}$, a surface porosity from 31 to $35 \%$ and a tortuosity from 1.9 to 2.0 .

2. EVA membranes possess higher values for pore radius and tortuosity than $\mathrm{RC}$ membranes.

3. The tortuous pore model combined with the $L_{p}$ and $P_{m}$ method is especially useful in the structural analysis of hollow-fiber membranes for clinical dialysis applications.

\section{Acknowledgment}

The authors are indebted to Mr. S. Yamane at Tokyo Tokatsu
Table 5. Calculation of pore radii $r_{p 2}$ and $r_{p 3}$ by $L_{p}$ method and $P_{m}$ method

\begin{tabular}{lcccc}
\hline & & \multicolumn{3}{c}{$r_{p 3} \times 10^{10}[\mathrm{~m}]$} \\
\cline { 3 - 6 } Dialyzer & $r_{p 2} \times 10^{10}[\mathrm{~m}]$ & Urea & Glucose & Sucrose \\
\hline MC 0.8H & 13.9 & 6.0 & 10.8 & 12.5 \\
TAF 10 & 16.4 & 6.0 & 10.0 & 13.0 \\
AM-10 & 12.4 & 6.0 & 10.7 & 12.6 \\
AM-2000U & 16.7 & 6.2 & 11.3 & 13.2 \\
KF-101 & 21.5 & 5.4 & 11.3 & 12.4 \\
KF-101C & 28.6 & 5.9 & 11.3 & 13.2 \\
B2-100 & 12.8 & 5.5 & 10.5 & 13.3 \\
\hline
\end{tabular}

Clinic, Chiba, Japan for help and advice with the analytical procedures of radioisotope-labeled solutes, and to Miss $R$. Yamamoto for typing the manuscript.

\section{Nomenclature}

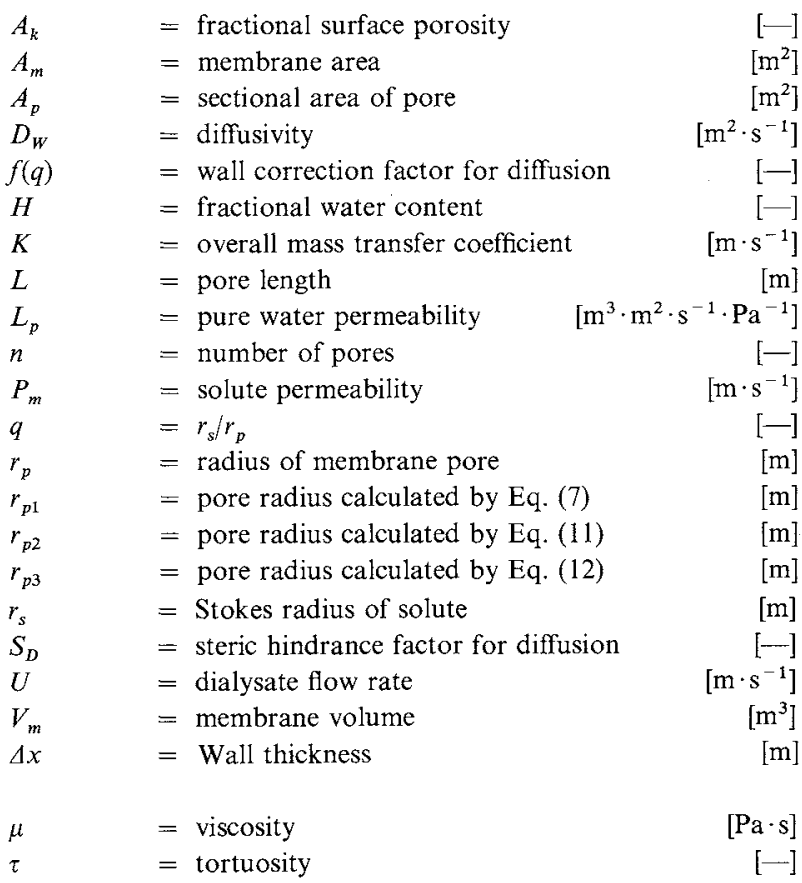

\section{Literature Cited}

1) Ferry, J. D.: Chem. Rev., 18, 373 (1936).

2) Kedem, O. and A. Katchalsky: Biochim. Biophys. Acta, 27, 229 (1985) 
3) Klein, E., F. F. Holland and K. Eberle: asaio J. 1, 15 (1978).

4) Klein, E., F. F. Holland and K. Eberle: J. Membrane Sci., 5 , 173 (1979).

5) Madras, S., R. L. McIntosh and S. G. Mason: Can. J. Res., B27, 764 (1949)

6) Nakao, S. and S. Kimura: J. Chem. Eng. Japan, 15, 220 (1982).

7) Pappenheimer, J. R., E. M. Renkin and L. M. Borrero: Am. J. Physiol., 167, 13 (1951).

8) Renkin, E. M.: J. Gen. Physiol., 38, 225 (1954).

9) Sakai, Y. and H. Tanzawa: J. Appl. Polym. Sci., 22, 1805 (1978).
10) Stevenson, J. F.: Am. Inst. Chem. Eng. J., 20, 461 (1974).

11) Stevenson; J. F., M. A. Von Deak, M. Weinberg and R. W. Schuette: Am. Inst. Chem. Eng. J., 21, 1192 (1975).

12) Takesawa, S., K. Ozawa, R. Mimura and K. Sakai: Japan. J. Artif. Organs, 13, 1460 (1984).

13) Verniory, A., R. Dubois, P. Decoodt, J. P. Gassee and P. P. Lambert: J. Gen. Physiol., 62, 489 (1973).

14) Wendt, R. P., E. Klein, E. H. Bresler, F. F. Holland, R. M. Serino and H. Villa: J. Membrane Sci., 5, 23 (1979).

(Presented in part at the 49th Annual Meeting of The Society of Chemical Engineers of Japan, Nagoya, April 1984.)

\title{
ON SECOND VIRIAL COEFFICIENTS OF GASES AND GAS MIXTURES
}

\author{
YUJI TANAKA AND DABIR S. VISWANATH \\ Department of Chemical Engineering, University of Missouri-Columbia, \\ Columbia, Missouri 65211, U.S.A.
}

Key Words: Gas, Gas Mixture, Virial Equation, Second Virial Coefficient, Third Parameter

\begin{abstract}
Molar refraction and molar polarization were used as new third parameters to correlate the second virial coefficients of nonpolar and polar gases, and their mixtures. A set of consistent data from the compilation of Dymond and Smith ${ }^{(6)}$ was used for the source data. The correlation was compared extensively with the correlations of Tsonopoulos, Tarakad-Danner, Brewer, Kubic and Vetere. In addition to the new third parameter, the utility of Pitzer's acentric factor was also tested. The correlation developed was of the general type
\end{abstract}

$$
B P c / R T c=\mathrm{f}^{(0)}(T / T c)+\kappa \cdot \mathrm{f}^{(1)}(T / T c)
$$

Where $\kappa$ is the third parameter.

\section{Introduction}

The non-ideal behavior of gases arising from intermolecular interactions in principle can be explained through the virial coefficients. The virial coefficients, either in pressure or reciprocal volume series, can be evaluated using potential energy functions such as the Lennard-Jones potential energy function.

The virial equation

$$
Z=1+B^{\prime} P+C^{\prime} P^{2}+\text { higher-order terms }
$$

or

$$
Z=1+B / V+C / V^{2}+\text { higher-order terms }
$$

is often truncated after the second term. There are several reasons for the use of $B$ only. For example, (i)

\footnotetext{
Réceived October 3, 1986. Correspondence concerning this article should be ad-
} dressed to D. S. Viswanath. experimental virial coefficients other than $B$ are rarely available, and even if available are of very low accuracy; (ii) when the virial equation is used for moderate pressures, it is sufficient to use the second virial coefficients; (iii) the virial equation by its nature diverges at higher density and therefore its application is limited in spite of the theoretical background; and (iv) virial coefficients higher than the third with the non-additive contribution have not been evaluated for potential energy functions other than the Lennard-Jones potential function.

Pitzer ${ }^{14)}$ did the first work on the generalization of second virial coefficients by introducing a third parameter, the acentric factor, $\omega$. Its applicability is limited to nonpolar and slightly polar compounds only. Also, experimental data of the vapor pressure at $\operatorname{Tr}=0.7$ is needed. Tsonopoulos ${ }^{18)}$ modified Pitzer's equation for polar compounds. This correlation with nine to eleven constants can predict the second virial 